Portland State University

PDXScholar

6-9-1976

\title{
A Comparative Study of Aristotle's Poetics and Ezra Pound's $A B C$ of Reading
}

Michael P. Hagensick

Portland State University

Follow this and additional works at: https://pdxscholar.library.pdx.edu/open_access_etds

Part of the Communication Commons

Let us know how access to this document benefits you.

\section{Recommended Citation}

Hagensick, Michael P., "A Comparative Study of Aristotle's Poetics and Ezra Pound's ABC of Reading" (1976). Dissertations and Theses. Paper 2259.

https://doi.org/10.15760/etd.2256

This Thesis is brought to you for free and open access. It has been accepted for inclusion in Dissertations and Theses by an authorized administrator of PDXScholar. Please contact us if we can make this document more accessible: pdxscholar@pdx.edu. 
AN ABSTRACT OF THE THESIS OF Michael P. Hagensick for the Master of Arts in Speech Communication presented June 9, 1976.

Title: A Comparative Study of Aristotle's Poetics and Ezra Pound's ABC of Reading.

APPROVED BY MEMBERS OF THE THESIS COMMITTEE:

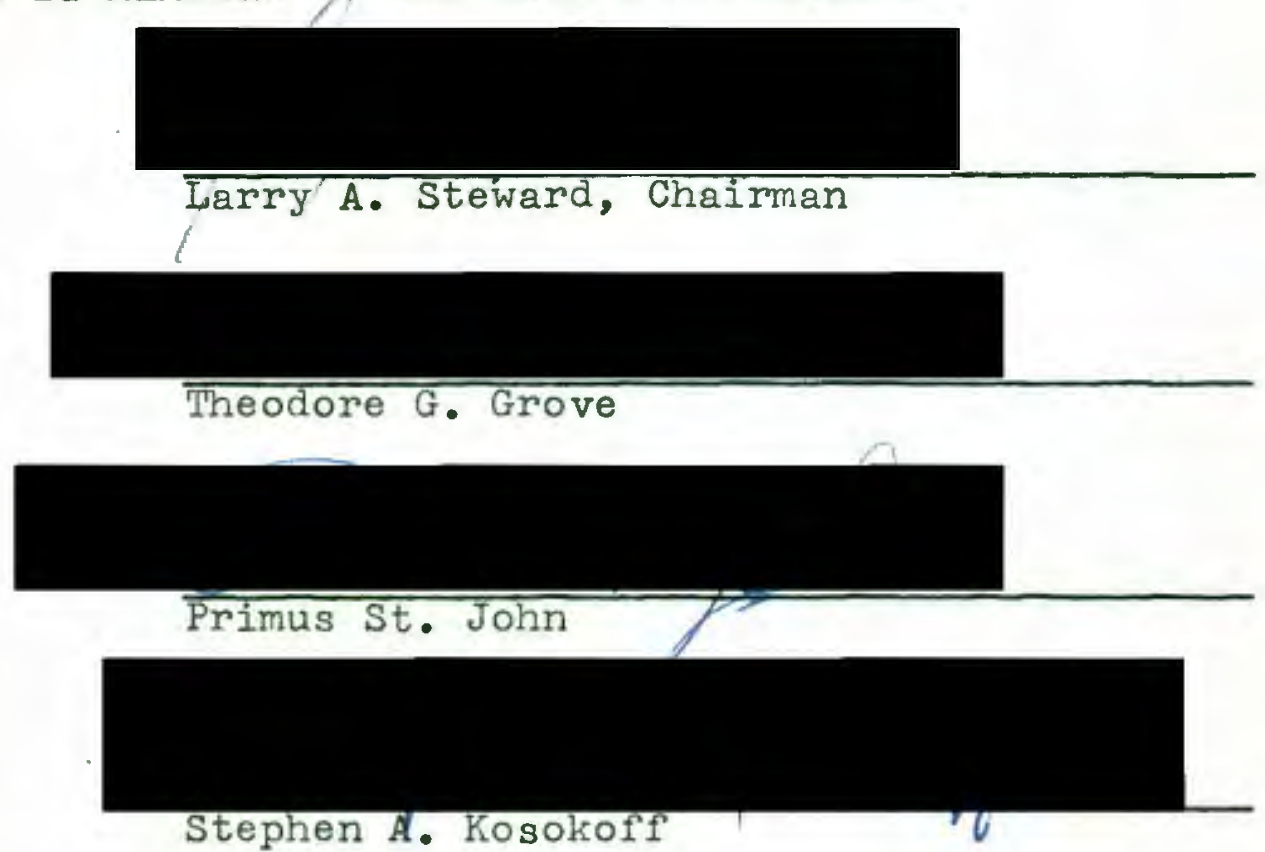

This paper is a comparative study of Aristotle's Poetics and Ezra Pound's ABC of Reading to discover and determine values in literature, especially poetry, which reflect on the nature and the manifestations of human communication. I feel that scholars in the field of communication can benefit personally and academically 
from exposure to those poets who have expressed themselves on the reasons or the manners in which people communicate. To pursue this question requires the use of a guide to poetry, a method by which I can learn to recognize a poem on sight; so that when it comes to discourse about the communicative values of poetry, I can be assured that it is poetry and not some other thing which would be the subject of discourse. The guide is called a poetics. From among the various texts on poetics I have selected these two because not only do they contain scholarship and observation of extraordinary acumen, but also because a comparison between the two can produce valuable similarities and differences, which are of further use in establishing values for a given text of poetics. The aims of this comparative study are: To stress the continuity of the tradition in poetics from the Greek classical culture to our own, to emphasize the advantages accruing to modern scholarship through a review of the documents from which a large portion of contemporary research and theoretical work derived, and to point out where the modern scholarship in poetics, that is Pound's, has improved on Aristotle's. The study is conducted to gain an understanding of poetry in its capacity to communicate, that is, to express the inarticulate stirrings of the intellect and emotions. To accomplish these aims 
and to arrive at a useful comparison it is necessary to correctly place each author. One must always keep in mind that Aristotle was a classical Greek, that he was a philosopher, not a poet and that his Poetics is allied to the rest of his philosophy and can only be understood in terms of the whole of his thought. On the other hand, Pound was an American, lived most of his life in the twentieth century, and he was not only a poet, but one who left a considerable quantity of poetry and critical material to posterity. In each author's text there is a main point about which the text circulates. This study will exern the principle issue in each text and provide this as a valid ground for comparison of any two texts of poetics. Finally the study mist determine the values which are in a volume about poetry which can lead the non-poet to poetry and poems. The treatise on poetry which does not put the layman in contact with actual poems, and provide a guide through this quantity, has limited usefulness qua poetics.

The application of the comparative method on these texts will yield a list of differences and similarities Since Aristotle's text preceeds any other chronologically, any subsequent text can be measured against it. Having determined where Pound's work is alike and dislike Aristotle's will bring the study arourd to its opening 
concerns, to begin a course of study which will ultimately enable the scholar in the area of human communication to benefit from the observations and experiments recorded, by writers on the nature and occurrence of communication, linguistic and non-verbal as well. The importance of this study lies not so much in its overt composition, but rather in the implications which such a study have for further studies of a cross-disciplinarian nature. The overview of the following text is that through a selection of proper guides and methods for instruction, the nonpoet can understand poetry well enough to avail himself of the instructive value of poetry as a medium for communication. 
A COMPARATIVE STUDY OF ARISTOTLE'S POETICS AND EZRA POUND'S ABC OF READING

\author{
by \\ MICHAEL P. HAGENSICK
}

A thesis submitted in partial fulfillment of the requirements for the degree of

\author{
MASTER OF ARTS \\ in \\ SPEECH COMMUNICATION
}

Portland State University

1976 
TO THE OFFICE OF GRADUATE STUDIES AND RESEARCH:

The members of the Committee approve the thesis of Michael P. Hagensick presented June 9, 1976.

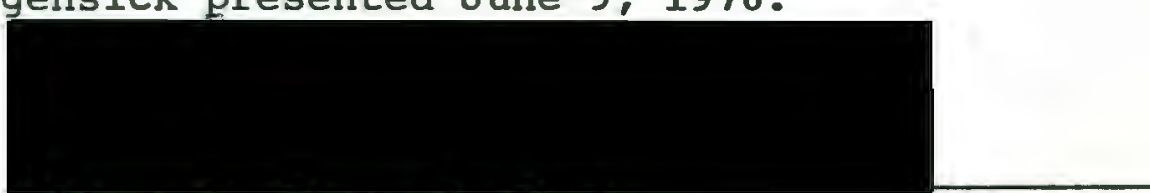

Larry A. Steward, Chairman

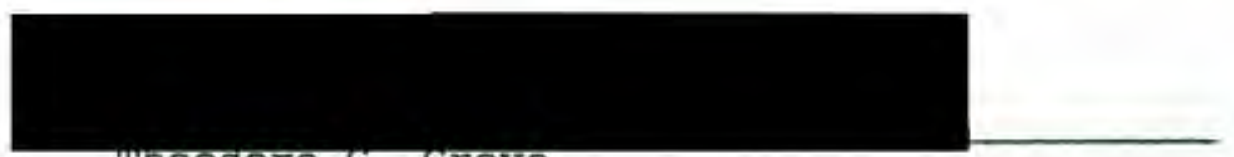

Ineodore G. Grove
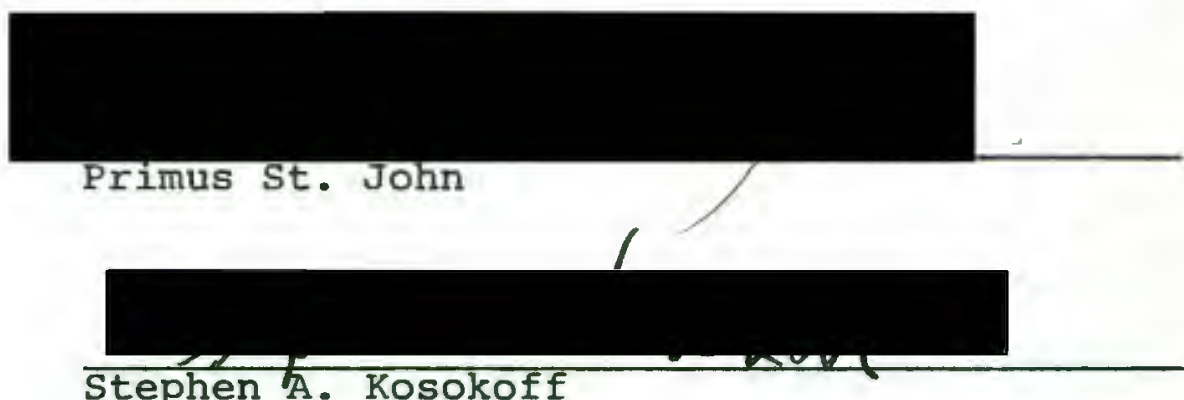

APPROVED :

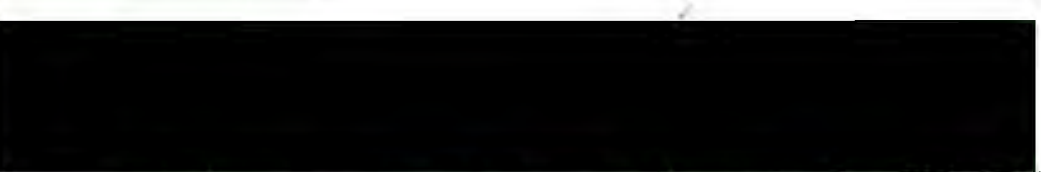

Robert W. Vogelsang, glead, Speegh Communication Department

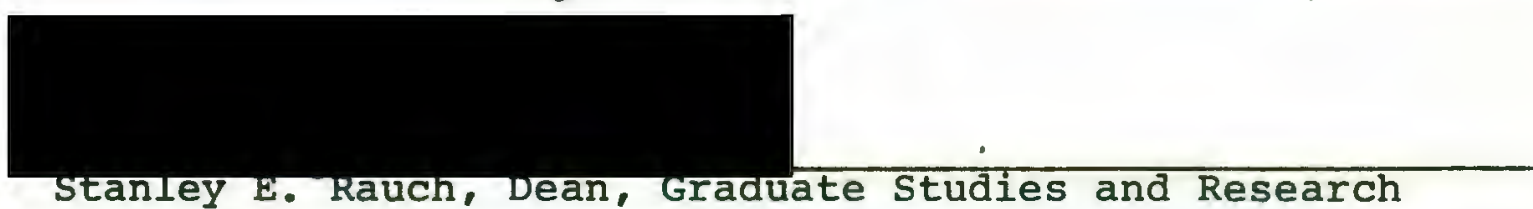


TABLE OF CONTENTS

CHAPTER

PAGE

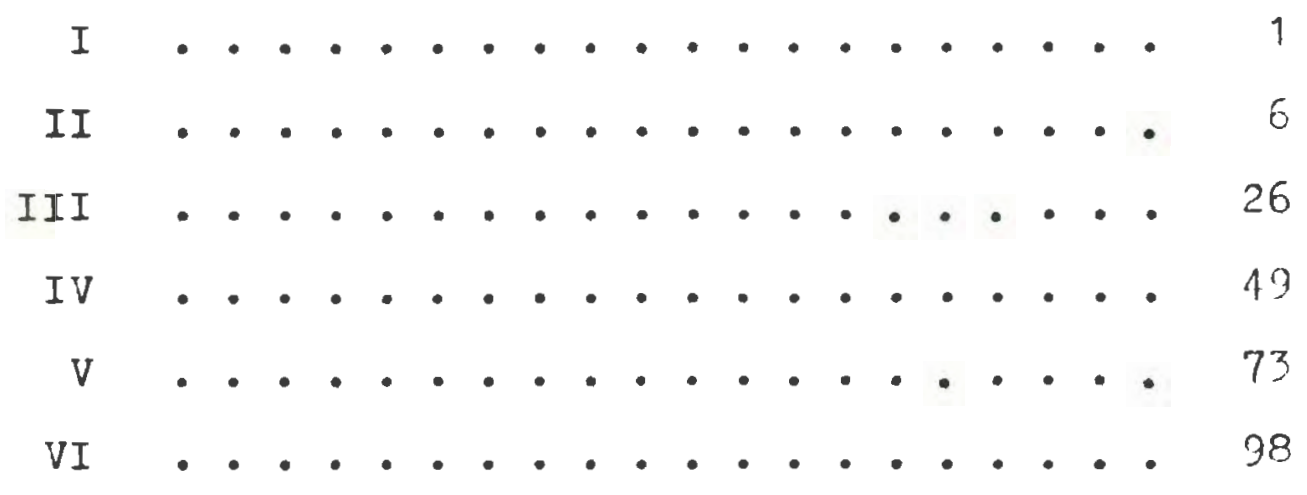

BIBLIOGRAPHY . . . . . . . 105 


\section{CHAPTER I}

This paper, a comparative study of the Poetics and the $A B C$ of Reading, has the purpose of determining the relative values of these texts for the discipline of communication. I have set a modern work, one in which the science of poetics has been brought to a remarkable precision, against the classical work in which we find the scope and methodology of poetics laid out for the first time in western thought. The paper is in four chapters, surrounded by introductory and concluding material. The first chapter will discuss the scope, purpose and function of the science of poetics and will define the limits and potential of a text on poetry. This chapter will include a short history of poetics in the West una closing comments on the value of a poetics text for the layman or the scholar who wishes to know what the art of poetry can offer regarding the nature and manifestations of human communication. The second chapter is devoted to the Poetics. An introduction to the manuscript itself and the physical remains upon which present editions are based will precede an outline of it contents. The main thrust of this chapter will be an understanding of the principle of mimesis, both Aristotle's use of the term and the development of this 
concept into the modern age. Chapter Three will present Pound's poetics and include the reasons which the author has offered for having written the book and an outline of the material in the text. The chapter will concentrate on the ideogrammic method as the chief concept. The fourth chapter will contain the grounds for comparison, those which this paper considers valid and those which are rejected herein. The chapter and the paper will conclude with a summary, set aside for fuller treatment, of the Iuminous items in the study.

This study was prompted by a desire to tap the resources of literature for clues to the nature and occurrence of human commication acts through the medium of linguistic expression.

To say more than human things with human voices, That cannot be; to say human things with more Than human voice, that, also cannot be; To speak humanly from the height or from the depth of human things, that is acutest speech. ${ }^{1}$

As I read in the various volumes of English language literature, it became increasingly apparent that not only has human communication been mentioned specifically in literature, but that the very structure and nature of literature might provide information for the comrunications scholar as to how and under what circumstances humans are moved to any utterance or to no utterance whatever. To secure a guide through the vast array of Iiterature directed 
my attention to poetics at which point I discovered that not all volumes called "poetics" did or said that same thing. Yet all volumes on poetry derived from Aristotle's text, so I set the Greek.master against subsequent scholars of poetry. To present the virtues of Aristotle's text, virtues through which the principles of poetic art can be transmitted to the non-poet, I chose to compare its substance with that of Pound's treatise because in Pound's poetics I found the study of poetry has been brought to as nearly precise a science as has been seen to date. The application of scientific method to the study of literature was Pound's aim, particularly in the examination and comparison of specimens of literature from which general principles can be drawn. In this sense Pound has taken the work of Aristotle and brought it in line with the rest of scientific inquiry. These points will be discussed more thoroughly in the third chapter. For the present it is enough to observe that this study intends to discover the values of the science of poetics in informing the non-poet of the origin and appearance of poetry, through the comparison of the originating work with a recent paradigm of poetic study. The study will direct itself towards the researcher or teacher of communications, who will be able to use literature in theory and pedagogy 
to illustrate and provide experimental materials for human communication models.

This paper will consist of three operations: One will determine the standards by which the two works will be compared. This is necessary because the entire works could be invalidly presented through faulty comparison. Given the state of the manuscript of the Poetics, the differences in classical and modern culture and language and the literature which each author was describing and analyzing, a valid comparison can and must be drawn on other lines than these. Ori the other hand, there are concepts central to each work which can be compared because they refer to the basic question of a poetics, the search for tine origin of the vork of erst. Another operation which will be performed, seeks to determine the usefulness of a given work on poetry to the non-poet or layman. A third operation will, in response to the first two, identify the characteristics by which a treatise on poetry might he tested to judge the validity of its concepts in vjew of the acturl literature described, and judge whether or not the author has seen the mark which distinguishes poetry from other forms of human discourse. 
I will perform these operations after presenting a background in the form of a short history of poetics. This historical portion of the paper will be narrative as well as analytical, and will be an encyclopedic overview and classification by types of the available texts on poetry. Most of the material here is gathered from standard works of reference, encyclopedias, dictionaries, bibliographies and anthologies of poetics. The reading of the text for the Poetics will come from the available English language translations, listed in the bibliography, notably those by Butcher, Bywater, Else and that printed in the Loeb Library edition.

In short the paper is an example of a task which, if performed on several texts of poetics, could yield information on the nature and functioning of human communication found in our literature. Through the comparative method the best texts can be separated from the mediocre texts and the best ideas in any text can be set against those of any other. Once the best text has been chosen, the values for a guide to the study of poetry can be firmly established, which values are clarity, accuracy and simplicity of presentation. This in turn is a stepping stone to the larger task of sorting through western literature, once we know what we are examining, for clues to communicative behavior of human kind. 


\section{CHAPTER II}

In this chapter I will present the scope, the subject matter, the purpose and function of the science of poetics. I will proceed to a discussion of values in the text of poetics, observing certain illuminating examples and finally to the needs of the non-poet, the layman or student who wishes education in literature. According to Thrall and Hibbard, poetics is:

A system or body of theory concerning the nature of poetry. The principles and rules of poetic composition are set forth. The term is used in two forms, POETIC and POETICS, with POETICS, the more common, referring both to the body of principles promulgated or exemplified by a poet or critic. The classic example, of course, is Aristotle's Poetics. ${ }^{2}$

$A_{S}$ we can see from the start, the Poetic's is itself the definition of poetics. The Encyclopedia of Poetry and Poetics assigns three tasks to poetics: 1 . It defines poetry and its various branches and subdivisions. 2. It discusses the principles that govern it. 3. It discusses the principles which distinguish poetry from other creative activities. 3

The relationships which obtain today between poetics and criticism are manifold and complicated. The task of critic is to choose primarily and then to evaluate and analyze the works before him. This presupposes a 
body of judgments and standards of judgment which in turn follow from a larger theory of aesthetics. The two extremes are to adhere to a rigid system or to reject all aesthetics together. The relationship is between poetics and the creative act itself. The question here is whether or not the poet begins with a theory of poetry and then composes poems to fit this theory or whether some other activity actually takes place which is only later defined as a theory. A poetics can also discuss the differences between prose and poetry, whether poetry must rhyme, or, when it rhymes, what the manner and form of versification is. Theories regarding the various types of literature, genres, is valid material for a poetics and is the nature of poetic insplration and the relationships between poetry and myth or the supernatural.

There is no uniquely valid way to classify theories of poetry; that classification is best which best serves the particular purpose at hand. All theorists recognize that poetry is a fabricated thing, not found in nature, and therefore contingent on a number of factors. 4

These factors are three: 1. That the poem is produced by someone called a poet. 2. That the subject matter of poetry is humanity. 3. That the poem is addressed to someone called an audience. Therefore the author of a poetics might begin with the poet and discuss only the activity of creation itself. He might also view poetry 
only insofar as it affects an audience or he might take the poem as a self-supporting entity to be regarded in isolation from the rest of the world. Premminger classifies four types of poetics: mimetic, pragmatic, expressive and objective.

The mimetic approach began with Plato who saw that "poetry is mimesis, or imitation, in which a mirror, turned round and round, can produce an appearance of all sensible things." 5 This view follows from Plato's thinking that the world itself is an imitation of a higher reality and thereby forcing poetry to compete with all other human activities in discovering the good, true or beautiful with the handicap that poetry has an imitation of the real world and hence an imitation thrice removed from ultimate reality. Moreover poetry was not composed, according to Plato, "by art and knowledge, but by inspiration, at a time when the poet is not in his right mind." 6 Aristotle also felt that poetry is a form of imitation, which it shares with the other arts, but his use of the term is not like Plato's.

In Aristotle's scheme, the forms of things do not exist in an other worldly realm, but are inherent in the things themselves, so that it is in no way derogatory to point out that poetry imitates models in the world of sense. 7

The mimetic theory contined through Cicero and Plotinus who demonstrated "that it was possible to assume a worldscheme which includes Platonic Ideas, yet allows the artist 
to short-circuit the objects of sense so as to. imitate the Ideas from which Nature itself derives." 8 This has the effect of taking poetry from the lowest of human activities to the highest, from the mere servile copying of things in the sensible world to the re-enactment of creative activity on a universal scale. Claims that poetry, qua art, put one in touch with elements beyond the common world or ordinary experience characterize much mimetic theory.

In his "Defence of Poetry" Shelley demonstrates the radically reductive tendency of an uncompromising Neoplatonic theory. Since all good poems imitate the same Forms, and since these Forms, as the residence of all values, are the models for all other human activities and products as well, Shelley's essay all but annuls any essential differences between poem and poem, between poetic kind and poetic kind, between poems written in various times and in various places, and between poems written in words and the poetry of all other men who "express this indestructible order."

Mimetic theories which hold that poetry imitates aspects of the sensible world have been more common than their more Platonic kin. Examples of this tendency include Charles Batteux who "found in the principle of imitation the clear and distinct idea from which he systematically deduced the nature and all rules of the various arts," Richard Hurd, who "declared that all poetry is imitation ...having all creation for its object" and Lessing, who discovered the essence of poetry "to be imitation and 
derived the bounds of the subjects each art is competent to imitate from the differences of their media." 10 This was during the eighteenth century. Since that time, "the mimetic doctrine has been more narrowly employed by proponents of artistic realism, or in theories limited to the more realistic literary genres."ll

Pragmatic theories see the poem in a means-end relationship and view the content of poetry from an essentially rhetorical standpoint. The prototype for the pragmatic approach is Horace's "Ars Poetica", "with its persistent emphasis that the aim of the poet, and the measure of poetic success, is the pleasure and approval of the contemporary Roman audiences and of posterity as well. 12

"Auto prodesse volunt, aut delectare poetae,"
Horace declared, although pleasure turns out
to be the ultimate end, with instruction re-
quisite only because the graver readers will
not be pleased without moral matter."li

In time these two functions of poetry were augmented with "movere", to move and the purpose of poetry was then considered to be to please, to delight and to move. Sidney "made moral profit the ultimate aim of poetry"; Dryden "subordinated instruction and emotion to the delight of the reader"; Johnson "insisted that the end of poetry is to instruct by pleasing."14 Pragmatic theories tend to regard the poem as a made object, a crafted product, 
designed to achieve known ends and regard the rationale of poetry as derived from the pleasure of the reader.

The chief historical source for the expressive theories of poetry is the treatise "On the Sublime" by Longinus. By contrast the mimetic poet holds the mirror up to nature, the pragmatic poet assembles his resources in terms of a given aim, but in the expressive orientation "the poet moves into the center of the scheme" and become himself the prime mover of the poem. In his treatise, Longinus defines sublimity in terms of its power to transport the poet into a higher state than usual life permits.

The influence of Longinus's essay, after it became generally known in the third quarter of the $17 \mathrm{th} \mathrm{c}$., was immense, and its emphasis on thought and passion, originally used to explain a single stylistic quality, was expanded and applied to poetry as a whole. 15

The effect of Longinus' doctrine on poetry was chlefly that of reinforcing the attitude that poetry is an emotional rather than a rational use of language. Wordsworth's "Preface" to the Lyrical Ballads show that he inherited much of the previous century's emotive treatment of poetry and became the single most important pronouncement of the emotive theory of poetry." 16 Thus poetry is seen as the outpouring of the poet who must above all things else express his feelings. There can be nothing calculated about the 
examined at length. The objective aspect of Aristotle's work became linked to Horace's poetics, and the effect of the poem on the audience became the supreme consideration. A radically new approach to an objective theory of poetry was. inaugurated by certain Italian thinkers of the Renaissance (including Cristoforo Landino, Tasso and Scaliger) who proposed that the poet or "maker" does not imitate God's World, but like the God of Genesis creates his own world, and, itywas sometimes suggested, "out of nothing."

In our own day, an objective theory of poetry appears in one form or another in various places. The emphasis upon text explication and the movement called "Russian Formalism have focused attention on the study of the pooms as such and developed methods for analyzing the internal, relations of its elements." 20 Thus we hear that the poem is a poem and nothing else, that the poem must be treated qua poem and that the poem is the object of the critic's concern, regarding the proper approach to the poem as "the intrinsic rather than the extrinsic study of literature (Wellek and Warren, Theory of Literature)."2l

The classification of theories of poetry or of texts of poetics or criticisms has been further complicated over time by time introduction of theories from psychology or sociology or political science into the body of criticism.

For example, sociological critics from Thomas Blackwell, Enquiry into the Life and Writings of Homer (1735), through Taine, V. L. Parrington, and the Marxist critics, regard the materials and values of a literary work as determined in large 
part by the geographical, social, economic and political conditions of its time and place, whether these enter a poem through the contemporary scene that is limitated, or by adaptation to the assumptions and prejudices of the audience that is addressed or as a precipitation of collective and superpersonal ideas and forces for which the poet merely serves as catalyst. 22

Others see the poem as the result of the interaction of the forms, techniques and materials of literature; this process is self-perpetuating. The complications which have arisen because of the interrelatedness of poetics and nearly all other aspects of human thought and activity have frequently lead critics and poets alike to openly reject forms of theorizing in the domain of poetic art.

The most recent and concerted attack of this sort has been launched by a group seemingly remote from the aesthetic impressionists: the philosophical analysts who take their departure mainly from the later lectures and writings of Ludwig Wittgenstein. 23

A number of positivist theoriticians disclaim any ability to formulate theories of poetry nor yet even any definition of art, because "there exists no procedure for deciding in favor of one or against another by empirical evidence or counter-evidence." 24 There is a grave misunderstanding among these positivists. They might contend that poetics is nothing more than the history of linguistic mistakes and illogical conclusions regarding the nature of poetry. On the other hand, even Aristotle himself would not suggest that anyone can learn the first 
thing about poetry without direct examination of the poems themselves. In our time it was Pound himself who made the most forceful and eloquent prenouncement on the necessity for observing the actual facts of literary production as prerequisite to any understanding of poetry in general. In fact the entire $A B C$ of Reading might be construed as an appeal to direct and personal observation of poetry and prose, with the reader urged to go in fear of abstractions. As Premminger summarizes the situation:

A valid poetic theory is empirical in that it begins and ends in an appeal to the facts of existing poems... Its statements are not to be judged by their empirical verifiability out of context, but by their function as stages in the total process of illuminating the qualities and structure of diverse poems. 25

This survey of poetics brief as it might be serves to illustrate four points: 1. There are types of poetics. Preminger saw four, the mimetic, the expressive, the pragmatic and the objective. Many poetics will be found to cover two or more of these types. 2. There are historical trends in poetics texts. Thus we began with Aristotle's simetic and occasionally objective approach to poetics which was soon qualified with Longinus' expressive concerns and the pragmatism of Horace. During the Middle Ages some form of Aristotelianism or Platonism dominated poetics as nearly everything else. In this case one's understanding of poetry is inevitably linked to ones cosmology or religion. For a few centuries 
the expressive concerns of Longinus resurged and underwent numerous alterations and metamorphoses. In the twentieth century we see most of the historical trends appearing in one fashion or another, frequently with an admixture of psychology, sociology, linguistics and political science. These historical trends in poetics texts can be reduced to five: 1 . There are those who believe that a poetics is possible and those who feel that it is not. Those who feel it is not feel this way either because they are "scientists" or "logicians" and the matter of poetry is unreachable or meaningless from their stance, or because they are poets and the matter of poetry is for poetry alone, all theories of poetics missing the point and being ultimately false. The logical positivists represent the former and a writer like, Anatole France the latter. 2. There are those who feel that the poem is what is important and others that the poet is more important than his work. An extreme objectivist might argue for the first case and the radical expressivist for the second. 3. There are those who would raise poetry to the heavens and those who would keep it earthy. The classic example of this argument is epitomized in Raphael's painting, "The School of Athens," in which Plato is seen with a copy of his Timaeus under one arm and the other arm pointed skyward, and Aristotle is seen beside him, a copy of the Politics under one arm and the other nearly straight 
out in front of himself. Thus the Platonists, believing that the sensible world is a reflection of a higher world, will be lofty in their poetics, whereas the Aristotelians, holding for the reality of earthly existence, will be more earthy. These three tensions mark much of the flux in poetic theory throughtout western thought. 4. Aristotle wrote the first poetics and all succeeding poetics must have taken that fact into consideration at least in definition. Plato mentioned poems and poetry from time to time but formulated no poetics as such, nor was he interested in doing so. Neither, however, could he afford not to observe that there are indeed things called poems and people called poets. Aristotle coined the word "poetics" and it is ours even to this day; he also stated the scope and function of his poetics and all succeeding poetics are a response and a criticism of Aristotle's efforts. 5. There is a need for a unified system of studying literature, which, based on a study of all previous poetics texts, will surpass what already exists in usefulness and accuracy. Usefulness can be determined by the efficiency with which a given poetic text educates, that is, leads the student forth to the poem itself, to the nature of poetry or to the work of poets. Accuracy is the relation of the poetics text to the facts or processes of the art of poetry. 
The value of a poetics depends on the needs of the student, beginning to investigate the art of poetry as a prospective writer, and the layman, who would know of the art and the craft of poetry as he now can know of geography or space science. There are five useful steps in learning which are applicable to the study of poetry: 1. Definitions. Before exploring any field one has to know what is being studied. In the case of poetry there are three key terms which must be defined to make the rest of the study at all comprehensible: i. Poetry. Is poetry the word for the work and the works of people called poets? Is poetry the force which calls poets to their task? ii. Poet. Is the poet the creator or the medium? How much of the poet's work is the poet, or is the personality of the poet irrelevant to an understanding of the poem. iii. Poem. This is the surest fact we have in the case of dead poets. Is the poem what we call the work of the poet? Is the poem the work itself or is it merely the ash left after the fire of creativity? Once the broadest scope has been defined we come to: 2. Types, classifications and nomenclature. In biology the student is given a chart which lists all the species and genuses, types and varieties of specimens in an orderly fashion. Such a chart can be constructed for poetry and literature with two understandings, one that the variety of poetry is at least as baffling as the variety of living 
things and another that such a system of classification must always be left open to accommodate the inevitable exceptions which assail a system too closed. 3. Processes. There are three processes which the student will wish to know: writing, reading and literary movements. What part of poetry is craft and what part inspiration? How much can be learned and what can never be taught? How can the student increase his understanding of poetry read or heard, determine the value of new pieces and place a given literary. manifestation among other works of letters? Wnat is the origin of literary movements? Who have participated in such movements, who have not? How have the various movements defined themselves and the items of their craft and art, or are there movements which eschew such definitions? How are the various literery movements related to other movements and other human activities? 4. Discoveries. In the sciences one might ask who discovered such and such a gas or compound, who developed a surgical technique or discovered a wonder drug. Who made the great discoveries in poetry? What are these discoveries and what has happened to them over the ages? These first four points are basically classroom or theoretical work. The last point is unique in that the student must become personalIy and physically and mentally involved. 5. Laboratory. To learn the parts of a cell a picture may do, but nothing is superior to looking at an actual cell through a microscope. 
What experiments, exercises or observations should the student conduct to learn the "anatomy and physiology" of the poem? These five steps could be easily worked into a text since the only equipment needed for laboratory work in poetry is pencil and paper and a suitably eclectic selection of poems.

I noted with some dismay that Premminger neglected to mention Pound's $A B C$ of Reading in his survey of poetics. The virtues of Pound's text are that he leads the reader to the poem by constant reference to the facts of literature, that he is useful to the beginner because he starts at the beginning, that is, he assumes the student is uneducated in letters and urges the student to begin his study anew if he has prior knowledge, that his objectives are clearly stated and fulfilled and that he recommends the laboratory method to accomplish the same goal that it does in other sciences. Thus the reasons for this comparative study can now be stated: 1 . To delineate the tradition in poetics from Aristotle to the present. As has been already observed, Aristotle wrote his poetics before anyone else and all poetics since then are to be seen in light of his work and are a form of criticism of that work. In comparing any subsequent poetics with Aristotle's one must ask whether the later work has done something, provided an insight, raised an important question, pointed to a new tendency or summed up the 
situation with greater accuracy and eloquence, which the earlier work has not done. 2. To express the debt which modern scholarship owes to the classics. Our poetics today are scholarship which was initially defined by Aristotle, who gave us the word, as well as the scope and function of poetics. A periodic review and examination of the classical work may easily prevent waste of time or duplication of effort, especially a less precise or useful effort, and also keep our perspective regarding the originality of our work from becoming bloated. 3. To discover where the modern work has improved in actuality over the classical. Once the values of the ancient work have been established they can be compared with the values in the modern work and thereby can the directions of future poetics be hined at. 4. To present the poetics of Pound. As I noted above, Premminger makes no mention of Pound's $A B C$ of Reading in his survey. I cannot surmise the reason for this other than that Pound's work is not considered to fall within the area of poetics. I have discovered, upon a careful reading of the $A B C$, that not only is Pound within the tradition of poetics, but that, in many facets of his work, he has outshone his rivals. I will elaborate more on the virtues of Pound's text in the fourth chapter. For the present let it be observed that the last two chapters of this paper will contain in part an apology, in the classical sense, for 
Pound's $A B C$ of Reading.

This chapter has introduced the central matter of the paper, a comparative study of Aristotle's. Poetics and Ezra Pound's $A B C$ of Reading. The objective is to discover standards for determining the values of a text of poetics through the application of pre-stated criteria for the purpose of the eventual examination of literature for information concerning the nature and manifestations of human communication. The rationale for this study is that the comparative method, when properly applied and conceived, is the best method for determining values in a text of poetics, and that the objective to learn about communication from literature is both realistic and relevant to the concerns of communication scholarship. The methodology is to present the background to the present work, specifically hisțorical and conceptual material which will make the study comprehensible, to present the works to be compared in fashion so that they can be compared, to perform a point by point comparison following questions designed to reveal the values searched for and to summarize the aims and objectives and tabulate the results of the study. A short survey of the history and types of poetics followed the introduction. Four essential points were distilled from the survey, thus justifying its inclusion here: 1. The types of poetics are discernable. 2. The history of poetics reveals 
principle trends in the discipline. 3. Aristotle's Poetics is the original conception of the discipline and stands well against its offspring. 4. A useful and accurate text of poetics is needed for the student, the layman, the interest scholar and the non-poet and must be found. The paper than discussed the values of poetics and how they might be discovered and the specific reason for searching out these values in Pound's treatise. 


\section{ENDNOTES}

$I_{\text {Wallace Stevens, "Chocorua to its Neighbor," }}$ from The Palm at the End of the Mind, 1971, p. 241.

$2_{\text {Thrall and Hibbard, A Handbook to Literature. }}$

3 Alex Preminger, Encyclopedia of Poetry and Poetics, 1965 , p. 636.

4 Ibid., p. 639.

5 Ibid., p. 640 .

6 Ibid.

7 Ibid.

8 Ibid.

${ }^{9}$ Ibid.

${ }^{10}$ Ibid.

${ }^{1 I_{\text {Ibid. }}}$

12 Ibid., p. 641.

13 Ibid., p. 642

${ }^{14}$ Ibid.

15 Ibid.

16 Ibia., p. 643.

17 Ibid.

18 Ibid. 


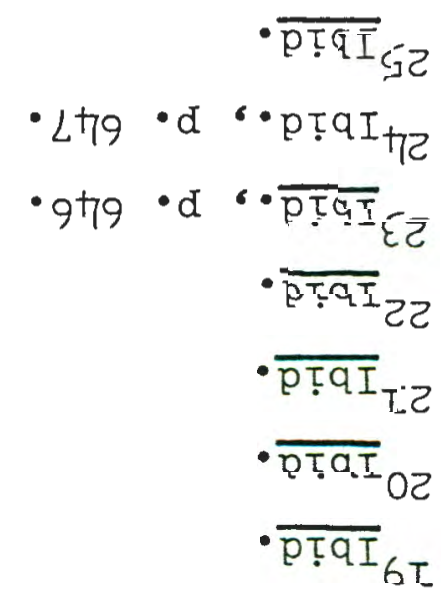


In this chapter I will present the Poetics of Aristotle in the following manner: 1. I will approach the physical evidence of the manuscript of the poetics from which present editions derive to provide background for the discussion of the material of the work, not so much to delve into the scholarship of ancient manuscripts as such. I will present comments on the condition of the manuscript as a text and enumerate some of the more frequent criticisms of the text. 2. I will outline the history of the manuscript, to include commentary on how the present edition came to be written and on its reception in modern times. 3. The major themes and concepts of the Poetics will be specified and discussed. 4. Finally I will discuss the central concept of mimesis, tell what it: is both to the Greeks and to the Modern scholars, specify why I feel the concept is central and elaborate upon the status of the concept today. All the work on Aristotle in this chapter is intended to make the poetics reveal its essential message and to put the document in such order that a fit comparison can be made in the fifth chapter.

The text of the Poetics has been supposed to have suffered more seriously than most prose 
Greek texts in the process of transmission; and many scholars accordingly have allowed themselves a very free hand in dealing with its difficulties.

These are the opening words to the introduction of Ingram Bywater's edition of the Poetics. Nuch of the difficulty in criticism of the text results from certain preconceived notions, inherited from the Middle Ages, about the nature of all writings from the library of the master of those who know. The text can be evaluated against the standards which have been set for the format and organization of modern published material, but the result of pulling Aristotle out of classical Greece and into the twentieth century is the invalidation of the resultant criticism. The texture of the poetics is not smooth.

The poetics begin fairly well, but as the work advances there are signsi of failing attention to form, and the statement becomes in places little better than a series of notes. The continuity of the exposition is frequently broken by parentheses, sometime on matters of very, minor importance for the immediate argument. ${ }^{2}$

Bywater proceeds to enumerate five anomalies of language or thought which he feels cannot be removed by the ordinary emendatorial artifices: 1. The anticipatory use of technical terms, which are defined afterwards. 2. Variations of terminology. Aristotle does not always adhere to the same terms even when dealing with the same technical ideas. 3. Inconsistency in the use 
of terms. 4. Inconsistency of thougnt. 5. Lapses of memory. ${ }^{3}$ Too many inconsistencies of these natures lead one to suspect either that Aristotle did not leave a finished manuscript in the first place, that what we have is not the work of Aristotle directly but rather the notes of his students, that scribes in recopying the manuscript made errors deliberately or inadvertently or that we simply have the wrong text today, that is, there exists somewhere a superior manuscript. Whatever the case the scholar must be advised from the start of his work that these difficulties are not to be ignored. Whether or not these anomalies effect our understanding of the essential thrust of the poetics is a matter to be taken up by each critic.

Bywater's outline of the contents of the text is suitably brief and complete to be inserted here in full:

1. A preliminary discourse on Tragedy, epic poetry, and Comedy, as the chief forms of imitative poetry, and the subject of the inquiry that is to follow (chaps. $1-5$ ).

2. Definition of a tragedy, and the rules for its construction (chaps. 6-22).

3. Rules for the construction of an epic (chaps. 23-24).

4. Enumeration of the criticisms to which an epic or tragedy may be subjected, and of the various possible replies to them (chap. 25).

5. A comparison of epic poetry and Tragedy, showing the artistic superiority of the latter (chap. 26):4 
The second section, that dealing with the rules for the construction of a Tragedy, has presented the chief difficulty for the critics. There are two main objections, one that chapters twelve and twenty are inter-polations, probably at the hand of some editor, and one that the remaining chapters are not in their proper order. A criticism of the manuscript in terms of artificially constructed norms regarding consistency or order in my estimation does violence to the text, because the critic faces all the extraneous data without ever coming to grips with the document as a whole. It has already been observed that when Aristotle flourished, there being no printing business to tell an author what order is called for, the standards by which we judge documents did not exist. Therefore, it seems clear that to continue discussing these standards and Aristotle's failure to adhere to them, beyond merely observing them so that one does not commit a grievous error in interpretation, defeats the purpose of exegesis, which is to get at the meaning and intent as well as the format of a work from antiquity.

Victorius was the first to see that the treatise now know as the Poetics is only the surviving portion of a larger work. The fact is sufficiently assured by the note in index of Aristotelian writings in Diogenes Laertius, who describes the work as being in two Books. We have no further direct testimony to the existence of a Second Book. 5 
The text of the Poetics, as.we now have it, may easily be seen to be only the first of two volumes. Bywater cites the concluding paragraph of the Poetics, the form of wnich is similar to that used by Aristotle in other paragraphs which mark transitions from one subject matter to another, and the faint tradition in some Aristotelian schools concerning a second book as evidence, together with Laertius' notation, tnat the present text is but half of a larger work. If loss of a second volume did occur then it is probable that the loss occurred during the papyrus period of the manuscript when the second volume was not attached to the first and suffered a different fate. The existing manuscript of the Poetics is entitled "Peri poietikēs", which indicates that the scribe know only of the one volume. Had therebeen two volumes at that time the title would have read "Peri poiētikēs $\bar{a} "$, or "About Poetics, Volume A". The second volume is supposed to have contained Aristotle's treatment of Comedy, but that is speculation.

Historically speaking, the manuscript is extremely obscure. The substance of the book seems to have been largely ignored in classical times. No ancient commentary on the text survives and there are relatively few citations among the ancients, acknowledged or unacknowledged. As Bywater observes: 
Several of the citations, too, are manifestly second-hand. This may be said also even of the reminiscences of Aristotelian ideas in Polybius, and in the Ars Poetica of Horace; for there is reason to think that Polybius was only following Eratosthenes, and Horace 6 his Greek authority, Neoptolemus

Although the manuscript we use today was written in the year 1000, there is "little or no indication of any interest in the book among the Greeks of the Middle Ages."7 Since, however, the Greek manuscript is predated by an Arabic and a Syriac version, we may conclude that the book had some readership in the East. Averroes wrote a commentary on the Poetics which was translated into Latin, under the title Aristotelis Poetria, by Hermannus Alemannus.

The Poetics were not among the many Aristotelian and otherphllosophic Greek books which found transltors in the thirteenth century, when the Latin occupation opened up the Byzantine world to the Westerns. The Rhetoric was translated at this time, but its fellow treastise was left out in the cold.

In the fifteenth century the Greek text itself became known among the learned in Italy; "and at the end of the century (1498) the first translation from it, that be G. Valla, was given to the world." 9 over the next two centuries a number of conflicting texts were printed and studied, but the manuscript which is considered to be the best reading of the work is called "A", Parisiuns 1741". The other manuscripts are referred to as apographs, 
or transcriptions, of this manuscript, particularly in view of the scholarship of Spengel (1865-66) and Vahlen (1857), who recognized "the unique authority of $A^{c}$ as the one record of the Greek textual tradition, and the ultimate parent of all our Renaissance texts."10

It is best at this point to leave the discussion of manuscript readings behind to concentrate on the more central issue, that of the themes and concepts in the Poetics, on the basis of which a valid comparison can be made with succeeding treastises on poetry. Else suggests fundamental reinterpretations of a number of major themes and concepts in the book, specifically:

1. Aristotle's idea of "imitation" and its relationship to the idea of creativity.

2. The conception of a musicless poetry.

3. Aristotle's "history" of poetry before Aeschylus: a logical construction rather than a genuine history.

4. Aristotle's views on comedy and the Dorian claim to its invention.

5. The so-called "unity of time."

6. The six "parts of tragedy" as moments in the art and process of tragic composition rather than parts of the poem.

7. "Catharsis" a feature of the structure of tragedy rather than an emotional end-effect upon the spectator.

8. The interrelations of catharsis, hamartia and recognition; the structural concept of tragedy.

9. The "perceptions that necessarily attend upon the poetic art." 
10. The four kinds of tragedy. 11. The definition of the epic and Aristotle's
ien of Homer. II. The concerns which Else has selected differ from those of Bywater in that Else's deal with the essential message of the Poetics, whereas Bywater's comments are directed to the physical evidence of the manuscript. This is not to suggest either that Bywater was not interested in content, nor yet that manuscript scholarship is out of place or irrelevant to an understanding of the complete document. For the purposes of this paper, since a comparison is the goal, it is more crucial to pierce into the meaning and intention of the work rather than to decide which of many readings is the preferred one. Moreover, of the eleven points for discussion listed above, only the first one, that of imitation or mimesis, will be singled out 2.5 the principle most central to Aristotle's thesis. The other ten have primarily to do with drama rather than the creation of poetry as such. I realize that to Aristotle the content of poetry stood opposed to the content of history, the former being an expression of what could or might be and, hence, more philosophical than the latter, which is the revelation of what has happened. That being the case, Aristotle would have naturally preferred to think that poetry in its best form was musicless verse moving towards the drama. Regardless, however, of the 
relationship of music to poetry, or poetry to drama or yet poetry to history, the fact remains that poetry is something created by human work, and mimesis refers directly to that creative activity.

Mimesis... is verbal and active in sense; not imitations or even modes of imitation, with the translators, but processes of imitation, imitatings. Its focus is not in the performance or presentation, nor even in the linguistic composition of the poem in words and verses, but specifically in the drafting of the plot..."12

Therefore, the notion that poetry, as an art, reproduces the sensible appearance of things, and this appearance only, is false. In the work of the drafting of the plot we have the artists most primitive stirrings to creativity, the point at which the inarticulate movements of the heart and mind defy the resistance of even a man devoted to silence against expression. To accomplish his end, it is true, the poet must learn the craft, how to construct verses, how to order the elements in the drama or what specific artifices must be used to complete the task of composition. But that is not what is meant by mimesis. Drafting the plot would seem to limit the use of mimesis to the classical Greek drama, but since that was the state of the art of poetry at the time of Aristotle, that is, the content of poetry oppossing the content of history, it is natural that Aristotle would associate mimesis with plot-drafting. Since Aristotle's 
day, however, the content of poetry and the trends in the content of poetry have changed so much so that verse poetry has virtually disappeared from drama (Eliot, e.g., notwithstanding), that the lyric mode has expanded and redefined the relationships between poetry and music and that the epic has almost died out, especially in the twentieth century. If by drafting the plot, on the other hand, is meant the impulse which initially seizes the poet in the presence of the circumstances of existence, then the concept of mimesis applies equally well to Aeschylus, Dante and William Carlos Williams. Furthermore, since Aristotle intended that mimesis apply to a category of human activities, of which poetry was one member, the concept must refer to more than drafting plots. Clearly Aristotle meant the term to refer to painting, sculpture, music, dance and poetry; of all the artictic activities the one common factor which he found was what he called this mimesis.

The upshot of the whole argument is now summed up: "Hence it is clear from these considerations that the poet ('maker') should be a maker of his plots rather than his verses." In translating such a statement it is hard to repress the terms 'creator' and 'creation'. This is, in fact, of all the passages in the Poetics, the one where the new Aristotlian sense of imitation and poetry (art of making) appears most

The distinction which I feel Aristotle is trying to make is that to master the craft of versification and 
to relate things in verse is not the essential task of the poet. A history rendered in verse or a treatise on biology put into couplets is not a poem, the poet, to be a poet, must make so ething new, "namely that structure of events in which universals may come to expression; and...he (Aristotle) regards this as the paramount duty of the poet." 14 The craft of versification, according to Aristotle, is not essential to poetry. What is essential is that the poet construct a plot, that is, that the poet imagine a state in which the population of his poems exist, in which the things and events of the poem can be present and in which the action is the probable but not necessarily the factual. Another important distinction to be made results from the translation of poietes, 'poet', or maker of the work of art, into the English creator, and the word poietikess into creation, in light of the association in English between this sense of creation and the creation of heaven and earth out of nothing by the Creator Himself.

Have not the English words 'creator' and 'creation' been damaged irreparably for this purpose by their prior association in our minds with God and His creativity? An omnipotent divinity can presumably create ex nihilo; and that idea has clung to the word. Poieters had no such connotation, even if applied (by exception) to a god. Plato plays with the term in Rep.10. 596d, put the idea is really carried by demiourgos. 15 
Nor is the poet a creator of things without regard to anything outside his personal sensibilities, but rather uncovers elements which already exist in the scheme of things and apprehends "true types of human character and represents what they will do or say under given circumstances."16 To write to the probable actions of types of human characters requires that the poet school himself first in the ways of humankind, become involved in as many facets of human activity as he can and immerse himself in the vortex of human interaction. Unless the poet knows the particulars of human existence his generalizations will be unfounded and hence meaningless. This is not to say that the poet writes of this actual activity among humanity, but rather, taking the raw material of his senses, after careful observation, and, through the process of mimesis, the poet creates a situation in which the most generalizing statements about men and women can be made.

A poet, then, is an imitator in so far as he is a maker, viz. of plots. The paradox is obvious. Aristotle has developed and changed the bearing of a concept which originally meant a faithful copying of pre-existent things, to make it mean a creation of things which have never existed, or whose existence, if they did exist, is accidental to the poetic process. Copying is after 拀e fact; Aristotle's mimesis creates

Aristotle has charged the word mimesis with a meaning that stands out from the usual Greek use of the term, and his work represents an advance in a series of 
advances in which the term developed greater and more luminous precision.

In literature the phrase (mimetikai technai, the imitative arts)...first occurs in Plato though, nor improbably, it may have been already current in popular speech as marking the antitheis between fine art and industrial production. 18

The objects of aesthetic imitation, according to Aristotle, are ethe, or "the characteristic moral qualities, the permanent dispositions of the mind, which reveal a certain condition of the will", pathe, the "more transient emotions, the passing moods of feeling," and praxeis, "actions in their proper and inward sense."19 Aristotle saw the poet as the imitator not of the external show of activity, not a kind of behaviorist, but rather as the inward energy which, moving outwards from the psyche of man, become manifest in concrete action.

A work of art is a likeness of reproduction of an original, and not a symbolic representation of it; and this holds good whether the artist draws from a model in the real world or from an unrealised ideal in the mind. 20

The difference here is that a sign or a symbol is a convention by which we refer to something, and this convention is arbitrary, there being no necessary connection between the symbol and the thing. Thus words do not belong to things but to mental states which occur when we are in the presence of things. Mental impressions, however, are "not signs or symbols, but copies of external 
reality, likenesses of the things themselves."2l In addition a work of art "reproduces its original, not as it is in itself, but as it appears to the senses."22 Thus it is that the work of art comes into being in the mental processes of the artist, who, having drunk his full of sensory revelation, conceives a mental image, which he then imitates by arranging the material of his art in sensible form.

The general question whether metre is necessary for poetical expression has been raised by many modern critics and poets, and has sometimes been answered in the negative as by Sidney, Shelley and Wordsworth. 23

It must be remembered that Aristotle was an observer of poetry, although I have seen one of his poems in an anthology, and from his point of view he wished to know what the proper vehicle is for the transaction of mimesis. Aristotle encountered samples of writing which were poetic in spirit but prose in form; this led him to extend his idea of poietess to include any language sufficiently charged with energy and meaning. He also had before him samples of writing which were metrical in form, but because they dealt with specific fact, not the imaginative probabilities which he saw in the best poetry, and thereby could not be considered poetry. Actually Aristotle does not support any extreme viewpoint regarding the relationship between poetry and verse. As Butcher explains, "The essence of the poetry is the imitation; the melody and the 
verse are the seasoning of the language."2h In short, without meter and verse a poem may fulfill its function as a mimetic art, but without these seasonings the complete charm and effect of the poetic expression may be dulled.

From the foregoing discussion of mimesis eight points emerge which merit reiteration: 1. The Aristotelian concept of mimesis is both active and verbal, a more precise rendering being expressed by the word imitating. The process of mimesis is more like the growth of a flower than the gyrations of a pencil sharpner. 2. Mimesis refers to a creative process; it is not a matter of servile copying. The artist recreates the sensible appearance of things and may even use illusion and metaphor in his work, but the work of art is the imitation of the mental image not the concrete facts of the material. 3. The artist must concentrate on the presencing of the true types. 4. The presencing of true types requires the artist to become experienced in anything which may be of value to his art, but the artist does not present things as facts, but rather he presents the imaginative probabilities of things. 5. The artist must reveal the presence of things, particular human actions, from the inward energy of the psyche outward to the world of sensible objects. 6. The objects of mimesis are three: ethe, the permanent dispositions, pathe, the transient emotions and praxeis, 
actions in their proper and inward sense. 7. The work of art is not a symbol, but a likeness. Even though poetry must use words which are symbols, the use of words by the poet does not call to mind some reality of which we are already dimly aware, but creates a new reality, an 'as-if' in which the contents of his poem can adhere and thrive. 8. Meter and verse are not essential to poetry, but are suitable and necessary seasoning when used in view of the main task of mimesis.

The status of the concept of mimesis in the twentieth century has been admirably discussed by John Boyd in his book, The Function of Mimesis and its Decline, especially, the epilogue.

Of course, one no longer seriously tries
to take on the universe in quite the confident
way of plato and Aristotle. But from Aristotle
at least, we have inherited a method that is
encouraging for any intellectual task, in
large or in small. This is the method of
metonymous realism, a method that looks for the
whole through a patient, teleological explora-
tion the parts experienced.25

To recapitulate, Aristotle saw the work of the poet characterized by the drafting of plots, in which the poet imitated the behavior of people from the inside out. In perceiving this mimesis as the heart of artistic work, Aristotle "divined what was at the heart of what was best in Greek culture."26 If the fulfillment of the mind was in contemplation, it was the Greek techne which put its 
seal upon the native activity in the mind. Through their thought, the Greeks were able to vivify twenty centuries of Western culture, but, as Boyd points out, by the eighteenth century this tradition was largely attentuated.

Though the skeletal framework of its discussions was still that of the Poetics, its substance had been largely lost and so one or another rhetorical form of moralism had thoroughly replaced pleasurable contemplation as the central function of poetry. 27

The result of this attenuation was that knowledge became more valued for the power it afforded than for the insights into truth which it provided. The course of mimesis throughout Western thought has become for Boyd a metonym for the state of Western cultural history. As he observed, "If mimesis truly feeds upon the richness of form in nature, this richness will be limited to a poem nourished in a less bountiful milieu." 28

After the extremest attenuation of the mimetic tradition, which characterized the eighteenth century poetic, the time was due for a recession of the mimetic cultural tradition and an advance of the modes of subjectivity.

For more than twenty centuries Western Man had been exploring the many corners of his first great intuition: that things are intelligible inasmuch as they are real. This "given" quality in everything was there to meet the first demands of the questioning mind and to color all its activities. Now 


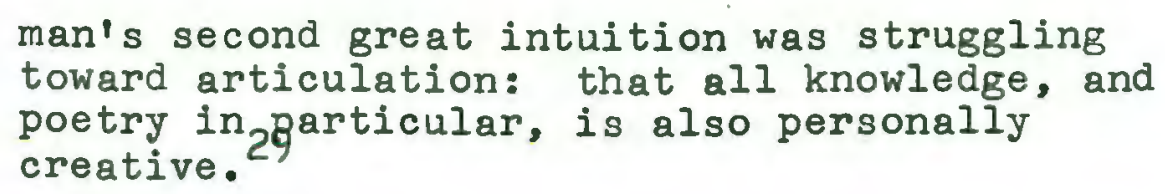

This subjectivity had been gaining momentum from the time of the Renaissance, but from the late eighteenth century onward much western thought was characterized by an awareness of this subjectivity. "The episte of poetic theory was probably among the greatest beneficiaries of this new subjective emphasis..." 30 This tendency of decline in the mimetic cultural tradition coincided roughly with what we saw above as the progression from the more objective views of poetics to the expressive persuasion articulated earlier by Longinus. The causes for the decline in mimesis are closely related to the prevalent philosophy of the time.

The poor appreciation of mimesis and its function at the end of the eighteenth century was clearly in great part the result of the poetic impact of the Enlightenment and its dehumanizing rationalism.31

Although, as Boyd observes, the critical comment on mimesis was frequently thin, rhetorical and moralistic in the period of the dawn of Romanticism, the mimetic tradition in literature maintained its vitality. He further notes that the objective and subjective interests in the thought of our culture reflect the "fundamental dynamic we should expect to find at work in the individual 
human mind..."32 This dynamic is such that the subject and the object are not in conflict but in harmony of the total growth of the individual.

This mimetic principle asserts the "given" quality which the Greek mind saw in all reality, hence its imitability; it maintains the stubborn autonomy of form in nature transformed into theme that is independent of private whim, structure that is fruitful in being self-sufficient, and pleasurable contemplation that needs no justification beyond itself. An yet there is always perfect harmony with a valid subjectivity. 33

Excessive subjectivity soon talks out its store of material. The sense of the "given" presents the mind with a neverending supply of new images. Excessive objectivity denies the image-making capability of the mind and, dwelling ordinately upon the data of the senses, soon loses coherence in a bewildering display of discrete impulses. The harmonizing influence of mimesis prevents the extremes of objective or subjective perception to cloud the images of the mind, precisely because, through mimetic activity, the artist reconciles the material world perceived through the senses and the ideal world which is formed in the imagination, each becoming the likeness of the other.

The ultimate tension in poetry, then, of subject and object is really the dynamic cooperation of" the "creative" and the "given." All true artists show a sense of this mimetic principle in the unselfish regard with which they view even their own work. There is a world of difference between being personnel and private. 34 
Even though the concept of mimesis appears central to the work of Aristotle, neither he nor any other classical author offers any adequate critical defense of this function. Perhaps it was that the term was so widely understood among the Greeks that he saw no need to belabor the obvious. The contemplative values of poetry, however, will see to it that the function of mimesis will never entirely decline, despite its poor articulation. This chapter has presented the Poetics of Aristotle in a form in which it can suitably be compared with Pound's $A B C$ of Reading for the purpose of determining direction and values in a text of poetics. The chapter opened with a presentation of the physical document itself and covered some of the more controversial issues concerning the reading of the manuscript. An outline of the argument of the Poetics followed the introduction, which was in turn by a review of the major objections to the substance of the text, to include linguistic and logical anomalies. The history of the manuscript most respected by scholars as the nearest to Aristotle's intent was presented and the unique authority of the $A^{C}$ manuscript in the Parisian codex was cited. The discussion then turned to the essential concepts and themes in the Poetics, of which it was said that the concept of mimesis was most central to the work, because through 
mimesis the poet is allied to the fine arts in opposition to the useful crafts. The classical notion of mimesis followed in presentation, which notion was summarized in eight points. Finally the status of the concept of mimesis in the twentieth century was described in terms of the cynamic in Western thought between the subjective and objective modes of conceptualizing the sensible world. This dynamic was seen to be analogous to the dynamic of the individual human mind in which these modes can either be in conflict and alternate for supremacy, or be in harmony and work as one for the personal development of the individual. 


\section{ENDNOTES}

Ingram Bywater, 1909, Aristotle on the Art of Poetry, p. xiii.

${ }^{2}$ Ibid.

Ibid., p. xvi.

$4_{\text {Ibid., p. xvii. }}$

Ibid., p. xxi.

'Ibid., p. xxiv.

7 Ibid.

8 Ibid.

9 Ibid.

${ }^{10}$ Ibid., p. xxvi.

${ }^{1 l_{G e r a l d}}$ F. Else, Aristotle's Poetics: The Argument, 1957, p. x.

$$
\begin{aligned}
& 12_{\text {Ibid., p. } 12 .} \\
& 13 \text { Ibid., p. } 320 . \\
& 14 \text { Ibid. }
\end{aligned}
$$$$
15 \text { Ibid. }
$$$$
{ }^{16} \text { Ibid., p. 320, footnote } 69 .
$$$$
17 \text { Ibid., p. } 320 .
$$$$
18 \text { Ibid., p. } 322 .
$$

${ }^{19} \mathrm{~S}$. H. Butcher, Aristotle's Theory of Poetry and

Fine Art, 1951, p. 121.

$$
20 \text { Ibid., p. } 122 .
$$


${ }^{21} \mathrm{~S} . \mathrm{H}$. Butcher, Aristotle's Theory of Poetry and Fine Art, 1951, p. 121.

22 Ibid., p. 125 .

23 Ibid., p. 127.

24 Ibid., p. 144.

${ }^{25}$ Ibid., p. 147.

26 John Boyd, The Function of Mimesis and its

Decline, p. 298.

27 Ibid., p. 299.

28 Ibid.

${ }^{29}$ Ibid., p. 300.

30 Ibid., p. 301.

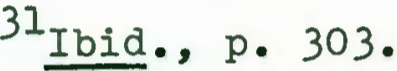

32 Ibid.

${ }^{33}$ Ibid., p. 304 .

34 Ibid.

35 Ibid., p. 305. 


\section{CHAPTER IV}

This chapter will present the $A B C$ of Reading, Ezra Pound's treatise on poetry, written in 1934. This chapter will unfold in four major sections: 1. Rationale. This will be an exposition of the author's own reasons for composing the treatise, which reasons bear directly on the further content of the text. 2. Outline. This will consist of a tabular display of the actual content of the text. 3. Key terms. Here I will single out the principle themes and concepts in the text and explain how they work together to form Pound's method of literary scholarship. 4. Ideogramic method. The final section will explore the implications of Pound's methodology visa-vis the ideal poetics.

\section{$\mathrm{ABC}$}

Or gradus ad Parnassum, for those who might like to learn. The book is not addressed to those who have arrived at full knowledge of the subject without knowing the facts. 1

The polemical paragraph which opens Pound's poetics sets forth in its direct and unambiguous prose, a major theme of the treatise, namely the need to prefer facts to dogma in the study of poetry. If we can imagine a time when the dominant authority passed pronouncements 
on the structure and processes of the physical world, matters which are now taken up by the many physical, earth and biological sciences we know, we might very well picture the state of the world which irritated Pound so much regarding the criticism of art, especially poetry. Pound saw all too clearly that the discoveries in the physical sciences which brought them out of the milieu in which authority and speculation took the place of observation and experiment, would be invaluable when applied to the investigation of literature. The primary thrust of his argument demands an unreserved respect for the facts of written material, books, poems, plays and songs, which are to be viewed as specimens in a laboratory, compared with one another, and only then generalized about, that is, distilled according to essence so that at the end one has a handful of theoretical statements which fit the facts accurately. This would force one to classify Pound's poetics with the objectivists, and up to a point this is permissible. Pound deviates, however, form theobjectivists merely in being more catholic in his tests for theory. The ideogramic method, which we will see below to be fundamental to Pound's thoughts on the art of poetry, is largely mimetic, and when the time comes in the fifth chapter to compare Pound with Aristotle, it will be shown that the similarities between mimesis and the ideogrammic method are uncanny. 
The $A B C$ of Reading is a textbook on how to study poetry; this approach to learning is nearly a cliche to our ears, and one calls to mind quickly an extensive list of "How to ...." books. Pound's method for the study of poetry differs from most books of this genre in that his requires intensive study, long hours, years of exposure to the material, as opposed to the learn anything-you-want-to-know in fifteen minutes motif.

The present book is intended to meet the need for fuller and simpler explanation of the method outlined in How to Read. How to Read may be considered as a controversial pamphlet summarizing the more active or spikey parts of the author's earlier critical sirmishing, and taking count of an enemy. The present pages should be 2 impersonal enough to serve as a text-book. 2

Pound deliberately directs the book to those who can read it for pleasure as well as for profit, specifically "those no longer in school;...those who have not been to school;...those who in their college days suffered those things which most of my own generation suffered." 3 Pound aims his treatise at the teachers of literature as well as the students, in hopes of making "even their lot and life more exhilarating and to save them from unnecessary boredom in the class-room."4 From this introduction three points emerge: 1. Pound's poetics is aimed at learners and students of poetry, not those, students or teachers, who have theories through which they view literature which are invalid against the facts 
themselves. Pound urges that the student empty his cup, that is, put aside everything concerning the nature and manifestations of literature as untested and hence of interest only after a careful review and study of actual examples of poetry. 2. Poetry, and consequently poetics, criticism and literary studies in general, is not only an academic subject, offered in departments of literature, but is rather one area of human life which can be observed and from which one can receive a sort of nutrition of impulse. 3. The material to which the student's learning is to be directed is not the doctrine of pound or any other writer on poetry, but the poetry itself, epics, songs, drama.

To outline the $A B C$ of Reading:

1. Introduction: $A B C$, or gradus ad Parnassum. How to study Poetry, statement of audience selection and general intent.

Warning: i. to avoid amibiguity and save the student's time is of paramount importance. ii. gloom and solemnity are out of place in the study of art to make glad men's hearts. iil. this book intends to make the best poetry popular.

2. Section I: Chapter One: An introduction to the ideogramic method and the arrangement of laboratory conditions in which the student can experiment on the poems.

Chapter Two: The definition of literature and poetry and a discussion of the use of language for human communication. 
Chapter Three: Here the author is most concerned with the relationship of literature to language and the both of them to society's life.

Chapter Four: The process of writing and the classes of writers occupies this chapter.

Chapter Five: Pound emphasizes the need to know the poetry of many languages, especially those most intimately connected with his own linguistically as well as through the history of letters.

Chapter Six: This chapter is a brief introduction to the benefits and drawbacks of reading translations.

Chapter Seven: A plea for establishing a solid foundation for the study of poetry and for understanding that the course of letters is roughly the same in any culture despite the obvious difference in idiom.

Chapter Eight: The preceeding material of this section is recapitualted at this point and the student is given five exercises designed to form the basis for his laboratory work: $i$ : Writing a clear sentence. ii. Describing something accurately. iii. Practicing meter. iv. Judging themes and determining the special knowledge of the author. v. Comparing and judging the values of particular authors.

3. Section II: Exhibits: These are samples of writing from Sappho to Whitman, selected to illustrate the points which have been made in the text so far. 
4. Treatise on Metre:
This is not an essay on versification in the traditional sense, that is, a description of the varieties of metrical and rhythmic forms which have appeared in poetry, but rather on the relationship of music to poetry, rhythm to emotion and to mathematics and thence again to poetry. To learn of the tonal qualities of poetry it is best to study music from. Pound's advice.

The major terms in the $\mathrm{ABC}$ of Reading, those upon which Pound's poetics turn are: I. The ideogrammic method. 2. The critic. 3. The classes of writers, six in all. 4. The ways of charging language with meaning, three in number. 5. Dichten = condensare. The ideogrammic method is one which Pound derived from two sources, the scientific method and the chinese written character. The expression 'scientific method' should not be taken too academically; the colloquial usage is perhaps closer to Pound's intentions. Essentially, he refers to one aspect of scientific method, that in which the scientist who wants to investigate some item, goes out to gather them in their natural setting and places one beside the other in his laboratory for examination and comparison and all this prior to the formation of theories about the items.

Scinece does not consist in inventing a number of more or less abstract entities corresponding to the number of things you wish to find out, says a French commentator 
on Einstein... The first definite assertion

of the applicability of scientific method

to literary criticism is found in Ernest

Fenollosa's Essay on the Chinese Written

Character. 5

The essay in question appeared in print in 1936, edited by Pound, under the title, The Chinese Written

Character as a Medium for Poetry. The assertions which appeared in the essay which appealed most to Pound were those which dealt with the relationships between the workings of nature, the cccurrence of language, the rise of poetry and the Chinese character as a metonym for the poetic process. There are seven points which stand out in Fenollosa's work: 1 . The purpose of translating poetry is infact the poetry itself and not the definitions of words as found in a dictionary. 2. Originally the form of the sentence followed from a direct observation of the phenomena of nature which the sentence then imitated. Thus to the modern mind, poetry is an attempt to remember the origins of language in the earliest observations of men and to recall that in the beginning all language was poetic, precisely in the metaphorical transference of the displays of nature to spoken and later written symbols. 3. True nouns do not exist in nature, that is, there are no things which are purely things without a touch of motion in them. Conversely there are no pure verbs in nature either because motion without something to move 
or move upon is equally impossible. 4. The Western method of defining words in a progression of increasing abstraction is basically contra natura and eventually selfdefeating. To define a tree as a plant moves one step farther from the tree. To define a plant as a biological organism is a greater abstraction. The only result of this method of defining words is that all definitions must sooner or later come to some modality of being or not being, the ultimate abstraction. By contrast the Chinese character 'defines' things by merely juxtaposing the contents of nature. 5. Poetry must render not merely what is meant by the words but what is said by them. Meaning is only a part of language, albeit an important one. The visual image which language can throw upon the mind was an aspect of language exploited by at an early time in his career. 6. Metaphor, the chief device of poetry, is at once the substance of language and by transference the substance of nature. The metaphor in this sense is a precise interpretive metaphor, not an ornament, through which the know interprets the obscure; thereby does poetry accomplish consciously what early poeple did unconsciously. 7. The poet selects those words for his poem which, when juxtaposed, blend with one another into a greater and more vivid harmony than the separate words themselves. 
To illustrate the capacity of the Chinese written characters to blend images and create a visual mimesis of nature, the following sentence is paradigmatic: The first character is the sun. The second shows the sun rising over the trunk of a tree. The third is the character for East or the Orient, and shows the sun tangled in the boughs of a tree, much as it would appear to an observer at dawn. The translation reads, The sun rises in the East.' Visually the mind is flooded with the brightness of the sun, not in one character only but in all three. It is this quality of the Chinese written language which interested Pound most urgently in his own theory of poetic composition and in his theory of poetic translation, namely the casting of the visual impression upon the mind. The critic, according to Pound, is one who chooses for himself, the word deriving from the Greek, krino, 'to choose, to pick out for oneself.'

The critic who doesn't make a personal statement, in re measurements he himself has made, is merely an unreliable critic. He is not a measurer but a repeater of other men's results.

This view of the critic accords well with Pound!s conviction that direct personal observation of the facts of literature is the only sure basis for speaking about literature at all. The facts of literature are the poems, plays and books which have been printed, and somehow made it to the public, through public performance 
or publishing. The task of the critic is to avail himself of the whole of literature, and from this to select those examples which reveal some extraordinary aspect of art, an aspect which is essential to the working of the art. Having made his selections the critic arranges them in such a way that the chief qualities of the art reveal themselves almost instantaneausly, not unlike Mendeleyev's chart of the elements or the taxonomy of biological specimens. This method stands in contrast to that method in which the critic, being, a Marxist, interprets literature as falling in two categories, one which supports Marxism and one which does not. This metnod also opposes psychological interpretations of literature, the Freudian, the Jungian analysis and criticism, spiritual evaluations of letters, philosophic: concerns which are extrapoetic, such as a positivist interpretation of literature, in short, anything not supported by the facts, and hence irrelevant to the study of literature.

Given the role of the critics as selectors of that kind of literature which teaches the most about literature, and as promoters of the best in literature among the society, Pound moves to classes of writers, which classes were proposed simply on the basis of the author's relative contribution to the course of Western letters. When you start searching for 'pure elements' in literature you will find that literature 
has been created by the following classes of persons:

1. Inventors. Men who found a new process, or whose extant work gives us the first known example of a process.

2. The masters. Men who combined a number of such processes, and who used them as well as or better than the inventors.

3. The diluters. Men who came after the first two kinds of writer, and couldn't do the job quite as well.

4. Good writers without salient qualities. Men who are fortunate enough to be born when the literature of a given country is in good working order, or when some particular branch of writing is 'healthy'. For example, men who wrote sonnets in Dante's time, men who wrote short lyrics in Shakespeare's time or for several decades thereafter, or who wrote French novels and stories after Flaubert had shown them how.

5. Writers of belles-lettres. That is, men who didn't really invent anything, but who specialized in some particular part of writing, who couldn't be considered as 'great men' or as authors who were trying to give a complete presentation of life, or of their epoch.

6. The starters of crazes. 7

Pound states without equivocation that until "the reader knows the first two categories he will nover be able to see the wood for the trees." 8 A reader may know much about books, have read many of them, may know for sure what he likes and does not like, but until the reader knows who invented the forms, the major concepts, in literature and who, on the other hand, brought some form to a high degree of excellence, and who copied whom, who turned out a 